\title{
Energy Returned On Investment of Engineered Geothermal Systems Annual Report FY2010
}

\author{
A.J. Mansure
}

DOE Award Number: DE-EE0002740

Background: why is it important to revisit the question: "What is the Energy Returned On Investment (EROI) of geothermal systems?" Past work is not only out of date, 1070's, but also includes methodological elements that need to be questioned. For example, is the embedded energy for cementing a well calculated using construction industry energy intensities representative of well construction? Furthermore, the assumptions of how to account for the energy needed to replace depleted production have not been justified. Thus significant work is needed to be able to provide a defensible EROI for Engineered Geothermal Systems (EGS).

Objectives for this year were to put in place all the requirements and tools necessary for the project and present the current status of our understanding of EROI of geothermal systems to both the Geothermal Strategic Planning and Analysis Working Group (GSPAWG) and the Geothermal Resources Council (GRC). These objectives were met.

Progress: as part of putting in place the tools needed, a baseline inventory of the materials for constructing EGS well was developed (Table 1). This inventory has been used to identify key data needed to proceed with an up-to-date analysis of EGS EROI.

The paper for the GRC Annual Meeting, "Review of Past Geothermal Energy Return On Investment (EROI) Analyses" includes an appendix that documents how, starting with a well plan, to develop an inventory of materials needed to construct a geothermal well. The example well plan used in the appendix was that documented by Polsky. ${ }^{1}$

Documentation of a baseline material inventory was included in the paper at the request of Argonne National Laboratory as part of their Live Cycle Assessment (LCA) of geothermal power production. The appendix of the paper submitted to the GRC provides sufficient detail to allow independent calculation of the materials and energy investment needed to construct the baseline well. Past work on geothermal EROI has not provided sufficient detail to allow independent assessment of input energy. Thus, the appendix is an important first step in reaching a consensus on EROI of EGS.

In addition to developing a material inventory, an estimate has been made of the energy needed to haul materials to the drilling location and to pump cement and hydrofrac fluid.

${ }^{1}$ Polsky Y., L. Capuano Jr., J. Finger, M. Huh, S. Knudsen, A.J. Mansure, D. Raymond, and R.J. Swanson, 2008, "Enhanced Geothermal Systems (EGS) Well Construction Technology Evaluation Report," Sandia Report SAND2008-7866. 


\begin{tabular}{|c|c|c|c|c|c|c|c|c|c|c|c|c|c|c|}
\hline & $\begin{array}{l}\stackrel{\widehat{D}}{\leq} \\
\bar{\Phi} \\
\stackrel{\Phi}{\infty}\end{array}$ & 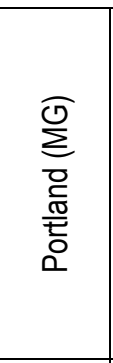 & 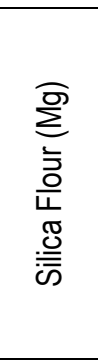 & 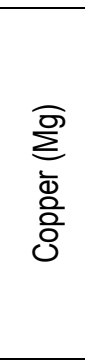 & 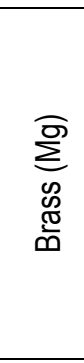 & 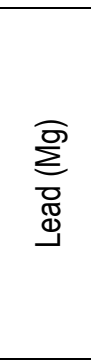 & $\begin{array}{l}\widehat{\widehat{\bar{\sigma}}} \\
\overline{\overline{0}}\end{array}$ & 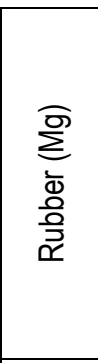 & 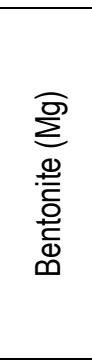 & 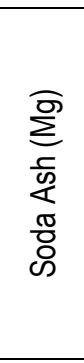 & 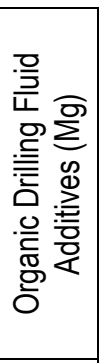 & 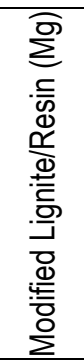 & 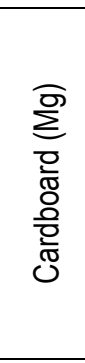 & 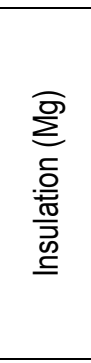 \\
\hline $\begin{array}{c}\text { Casing } \\
\text { Cement } \\
\text { Drilling fluid } \\
\text { ESP } \\
\text { Pipeline }\end{array}$ & $\begin{array}{l}40.7 \\
52.3\end{array}$ & 772 & 275 & 3.10 & 0.64 & 0.001 & 0.02 & 1.04 & 280 & 4.66 & 21.1 & 7.91 & 3.40 & 3.45 \\
\hline Total & 1,386 & 825 & 275 & 3.10 & 0.64 & 0.001 & 0.02 & 1.04 & 280 & 4.66 & 21.1 & 7.91 & 3.40 & 3.45 \\
\hline GJ/unit & 17.4 & 5.8 & 0.116 & 30.6 & 84.4 & 29.2 & 45.5 & 43.9 & 1.396 & 12.9 & 90.0 & 2 & 35 & 30 \\
\hline Energy (TJ) & 24.1 & 4.8193 & 0.032 & 0.095 & 0.054 & $<.001$ & $<.001$ & 0.046 & 0.39 & 0.06 & 1.903 & 0.016 & 0.119 & 0.103 \\
\hline
\end{tabular}

Table 1: Summary of materials per well.

Weight of other steel, non-casing, has been determined to be $\sim 0.1 \%$ of the weight of casing and thus, as anticipated, is insignificant compared to the casing. Similarly the energy to pump the cement is less than $\sim 0.2 \%$ of the energy to construct an EGS well and is thus insignificant. On the other hand, preliminary estimates of energy to pump hydrofrac fluids indicate that energy may be significant enough to be on the order of a few percent of the energy to construct an EGS well, thus the need for better data on hydrofracing.

Haulage has been calculated for the rig, casing, other steel (BOP, wellhead, bits, etc.), surface piping, water, cement, drilling fluid materials, and fuel. Rig (National 1625) mob and demob was assumed to be amortized over the drilling of 16 wells. Haulage distance for the rig, other steel, cement, and drilling fluid materials was assumed to be Bakersfield to Reno plus 100 miles. Haulage distance for the casing and pipeline was assumed to be Port of Los Angeles to Reno plus 100 miles. Fuel and water were assumed to be available locally 50 miles from the site. Water haulage includes drilling fluid, pipeline construction, and hydrofracing water. Water in cement was assumed to be part of cement (hauled with cement dry goods). All distances were assumed to be round trips; however, since the rig and BOP's would be returned to Bakersfield and the end of the job, two round trips was assumed for these items, one at the beginning of the project and one after 16 wells have been drilled. The reason for such details in calculation of haulage is because the fuel needed to haul material to the drilling location has been found to be more significant than expected.

Haulage fuel has been calculated to be $18 \%$ of the fuel used during drilling the well planned by ThermaSource. $^{2}$ From an energy perspective fuel needed for haulage is $\sim 9 \%$ of the energy to construct the well.

${ }^{2}$ Polsky Y., L. Capuano Jr., J. Finger, M. Huh, S. Knudsen, A.J. Mansure, D. Raymond, and R.J. Swanson, 2008, "Enhanced Geothermal Systems (EGS) Well Construction Technology Evaluation Report," Sandia Report SAND2008-7866. 
There are aspects of past analysis of geothermal power production EROI that merit further investigated if the background information can be located (e.g. Republic Geothermal 1979 report $^{3}$ and details about energy intensities used in past work). However, adequate information has been found to identify significant areas where technological improvements have reduced the energy investment necessary to build and operate an EGS power production facility: improved bit performance, reduced power plant embodied energy, and reduced wellfield pipelines embodied energy. Also EGS well productivity has improved since the 1970's, c.f. Fenton Hill vs. Soultz. Analysis of past work has identified significant energy demands as rig fuel, casing, cementing, wellfield pipelines, and the power plant.

Significant issues remain in understanding geothermal EROI: the impact of labor and services, wellfield productivity, and how depleted production will be replaced. While further review of past work on geothermal EROI would be desirable if the data resources can be found, work has progressed sufficiently to proceed to determination of an up-to-date EROI of EGS.

Status:

\begin{tabular}{|l|l|l|l|}
\hline Plan (DOE) & Plan (AJM) & Actual (DOE & Actual (AJM) \\
\hline$\$ 17,442$ & $\$ 6,558$ & $\$ 17,023$ & $\$ 6073$ \\
\hline
\end{tabular}

Work is progressing ahead of schedule. Presentation of the GRC paper in October 2010 will complete the first milestone of the project. Scheduled work for next year will result in an up-todate determination of EGS EROI. Work will include analysis of specific embodied energies that are not directly derived from the inventory analysis such as embodied energy of cementing and hydrofracing. Results from Argonne's LCA of geothermal development will be incorporated into this project. A strategy will be developed for how to include the impacts of reservoir productivity and depletion in the determination of EGS EROI.

${ }^{3}$ Republic Geothermal, 1979, "Industrial Assessment of Drilling Completion and Workover Costs of the Well and Fracture Subsystems of Hot Dry Rock Geothermal Systems." 